\title{
EVOLUÇÃO ESPAÇO-TEMPORAL DO USO E OCUPAÇÃO DA TERRA NO CORREDOR FLUVIAL DO RIO PARAGUAI, PANTANAL SUPERIOR - BRASIL
}

\author{
SPACE-TEMPORAL EVOLUTION OF THE USE AND \\ OCCUPATION OF THE LAND ALONG THE PARAGUAY \\ RIVER'S CORRIDOR, UPPER PANTANAL - BRAZIL \\ EVOLUCIÓN ESPACIO-TEMPORAL DEL USO Y OCUPACIÓN \\ DEL SUELO EM CORREDOR FLUVIAL DEL CURSO SUPERIOR \\ DEL RÍO PARAGUAY, PANTANAL - BRASIL \\ Gustavo Roberto dos Santos Leandro - Universidade Estadual Paulista - Presidente Prudente - São Paulo - Brasil \\ gustavogeociencias@hotmail.com
}
Flávio Rodrigues do Nascimento - Universidade Federal do Ceará - Fortaleza - Ceará -Brasil flaviogeo@bol.com.br

Célia Alves de Souza - Universidade do Estado de Mato Grosso - Cáceres - Mato Grosso - Brasil

celiaalvesgeo@globo.com

\section{Resumo}

Esta pesquisa foi realizada no município de Cáceres, Mato Grosso, no trecho do rio Paraguai, Pantanal Superior - Brasil, e seu objetivo foi analisar as mudanças de cobertura com o avanço do uso e ocupação da terra no período de 1980 a 2013. Para tanto, imagens LANDSAT foram georreferenciadas, classificadas e processadas; e as classes temáticas, quantificadas e editadas. Aliado aos procedimentos de gabinete, trabalhos de campo foram realizados, os quais permitiram a identificação das principais formas de uso das margens e dos canais do sistema fluvial. A pesquisa evidenciou que a principal atividade econômica desenvolvida é a pecuária, com valores gradativos ao longo dos anos - a área ocupada por pastagem mais que dobrou de 1984 para 2003. Os resultados evidenciaram importantes transformações na paisagem com significativas supressões da cobertura vegetal, ou seja, no período analisado, em mais de $50 \%$ da área houve algum tipo de transformação - desmatamento ou conversão de usos (áreas de pastagem para expansão urbana). Em relação às margens do canal, obras de engenharia foram as principais alternativas adotadas, a fim de conter os processos erosivos, sobretudo no perímetro urbano e em trechos côncavos, paralelos a BR-070.

Palavras-chave: Sistema fluvial. Mudanças na paisagem. Uso e ocupação. Ambientes agradacionais e denudacionais.

\section{Abstract}

This research was carried out in Cáceres - Mato Grosso, on the Paraguay River, upper Pantanal - Brazil, and its objective was to analyze the changes of coverage with the advance of land use and occupation along the period from 1980 to 2013. Thus, images LANDSAT were georeferenced, classified and processed, while the thematic class, quantified and edited. In addition to the cabinet procedures, fieldwork was carried out, which allowed the identification of the main ways of using the banks and channels of the river system. The research showed that the main economic activity developed is cattle ranching with gradual values over the 
years - the same more than doubled from 1984 to 2003. The results evidenced important transformations in the landscape with significant suppressions of the vegetal cover, that is, in the period analyzed, in more than $50 \%$ of the area there was some kind of transformation - deforestation or conversion of uses (pasture areas for urban expansion). Concerning to the edges' channel, engineering repairs were the main alternatives adopted to contain the erosive processes, especially in the urban perimeter and in concave sections, parallel to BR-070. Keywords: Fluvial system. Landscape changes. Use and occupation. Pleasant and denudational and aggradational environments.

\section{Resumen}

Este estudio se llevó a cabo en el municipio de Caceres-Mato Grosso, río Paraguay, Pantanal Superior - Brasil. Pretende analizar los cambios de cobertura con incremento en el uso y ocupación del suelo en el período de 1980 a 2013. Con este fin, LANDSAT fueron georeferenciadas, clasificados y procesados y las clases temáticas, cuantificado y editado. Procedimientos en la oficina y trabajo de campo fueron también llevado a cabo para la identificación de las principales formas de uso de los márgenes y los canales del sistema del río. Los resultados fueron: La principal actividad económica es la ganadería con valores graduales con los años, la misma se duplicó entre 1984 y 2003. Los resultados mostraron importantes transformaciones em paisaje con importante pérdida de cubierta vegetal, en más del $50 \%$ de la zona que era algún tipo de transformación - deforestación o creación de áreas de pasturas o de expansión urbana. Sobre los bordes del del canal del río, trabajos de la ingeniería fueron las principales alternativas adoptadas para contener los procesos de erosión, especialmente en el perímetro urbano y las secciones cóncavas, paralelas al BR-070.

Palabras clave: Sistema de río. Cambios de paisaje. Uso y ocupación. Entornos, agradacionais y denudacionais

Introdução

Os sistemas aluviais e as planícies de inundação respondem intensamente a alterações na dinâmica dos rios. Hoje, os ecossistemas (terrestre e aquático) situados em planícies aluviais de águas interiores estão entre aqueles com maior pressão antrópica, sendo o impacto das atividades humanas por ações diretas ou indiretas (Comunello, 2001). Nesse sentido, estrutura dos ecossistemas vem sendo ameaçada pelas formas de ocupação do território e da utilização das águas que para ali convergem (Pessoa et al., 2014).

No Brasil, os estudos de Borges (2004), Coelho (2007), Rocha (2009), Bayer (2010) e Bayer e Zancopé (2014) apontam disfunções na dinâmica ambiental de importantes bacias hidrográficas como as dos rios Paraná, Doce e Araguaia, com ênfase aos seus sistemas rio-planície de inundação. As evidências são aferidas ao considerarem mudanças nos processos associados à hidrodinâmica, bem como na morfologia de seus ambientes em virtude do uso da terra.

Em regiões do estado de Mato Grosso, pesquisas recentes relacionadas à apropriação do solo na bacia do Alto Paraguai têm demonstrado inúmeros impactos negativos nos ambientes fluviais, como 
assoreamento de canal e supressão da floresta aluvial (Vendramini et al., 2012). Souza et al. (2012) apresentaram as mudanças de uso no corredor fluvial e a relação com a sua evolução morfológica do sistema. Pessoa et al. (2014) demonstraram a evolução de atividades econômicas nos últimos vinte anos, sobretudo aquelas até então inexistentes. E, ainda, trabalhos que apontam conflitos de uso e ocupação com a legislação ambiental no corredor fluvial (Silva; Souza, 2012).

Portanto, a região Sudoeste de Mato Grosso não é imune a tais apropriações e por isso as constantes mudanças socioespaciais a partir dos modelos de produção têm gerado implicações diretas nos recursos hídricos e ambientes fluviais. Nesse contexto, o presente estudo analisa as mudanças de cobertura com o avanço do uso e ocupação da terra no período de 1980 a 2013 e os impactos associados no corredor fluvial do rio Paraguai, Pantanal Superior, Brasil, com ênfase na região de Cáceres, Mato Grosso.

\section{Procedimentos metodológicos}

Para análise espaço-temporal da cobertura vegetal e uso da terra, a proposta de Pessoa et al. (2013a) foi adotada. O trabalho contou com o comprimento das seguintes etapas: registro de imagens, recorte, segmentação das imagens, classificação supervisionada das imagens, quantificação dos dados e elaboração dos mapas temáticos para subsidiar a análise e discussão dos resultados.

Para o registro foi necessário a aquisição das imagens do satélite Landsat 5 TM e Landsat 8, órbitas/pontos: 227/71 relativas aos anos de 1984, 1993, 2003 e 2013, mês de junho (período de vazante). As imagens foram processadas no Sistema de Processamento de Informações Georreferenciadas - software Spring versão 5.1.7. Inicialmente, foi criado um banco de dados, utilizando-se o sistema de coordenadas UTM, datum Córrego Alegre e, fez-se o registro das imagens Landsat usando as imagens Geocover do ano de 2000 em formato GeoTiff, utilizando as bandas 3, 4 e 5 com resolução espacial de 28,5 m, no modo tela a tela (Pessoa et al., 2013a).

O registro das imagens consistiu na obtenção de 20 pontos de controle por imagem, considerando a distribuição dos pontos em toda a sua superfície. Na sequência foi realizado o mosaico das imagens, com posterior recorte que utilizou a base cartográfica digital da região como 
máscara. Para tanto, foi adotado o Método Tela a Tela com o polinômio de segundo grau.

A segmentação pautou-se na utilização do método de crescimento de regiões, e por meio do método exploratório foram definidos os limiares de similaridade e área. $\mathrm{O}$ valor da similaridade corresponde à variação máxima que pode ocorrer no nível de cinza de um pixel para que este seja declarado como pertencente a um segmento de pixel conexos vizinhos.

As classes de cobertura foram definidas a partir de levantamentos junto aos relatórios do Projeto de Conservação e Utilização Sustentável da Diversidade Biológica Brasileira (PROBIO) (Brasil, 2004) e dos Manuais técnicos em Geociências: manual técnico da vegetação (IBGE, 2012).

Com a finalidade de verificar a confiabilidade dos mapas gerados no Spring 5.1.7, foi realizada uma avaliação da exatidão por meio do Índice Kappa, que correspondente à razão entre a soma da diagonal principal da matriz de erros e a soma de todos os elementos dessa matriz, representadas pelo número total da amostra. Para a sua aplicação foram selecionadas 628 amostras tendo como referência o número total de classes de interesse (Cohen, 1960). O índice Kappa varia de -1 a 1, e quanto mais próximo de 1, maior a precisão da classificação (Silva, 2003). De acordo com Landis e Koch (1977), a qualidade da classificação pode ser definida em função dos seguintes intervalos de índice Kappa: $[<0,00]$ : muito ruim; [0,00 - <0,20]: ruim; [0,20 - <0,40]: aceitável; [0,40 - <0,60]: bom; [0,60 - <0,80]: muito bom; [0,80 -1,00]: excelente. A validação do índice foi correlacionada com os trabalhos de campo a partir da observação e caracterização.

Associado às técnicas e aos procedimentos de gabinete, foram realizados trabalhos de campo com o intuito de validar os usos predominantes das margens do canal e sistema fluvial (Figura 1). 
Figura 1- Pontos utilizados como referência para a identificação das principais formas de uso e impactos associados

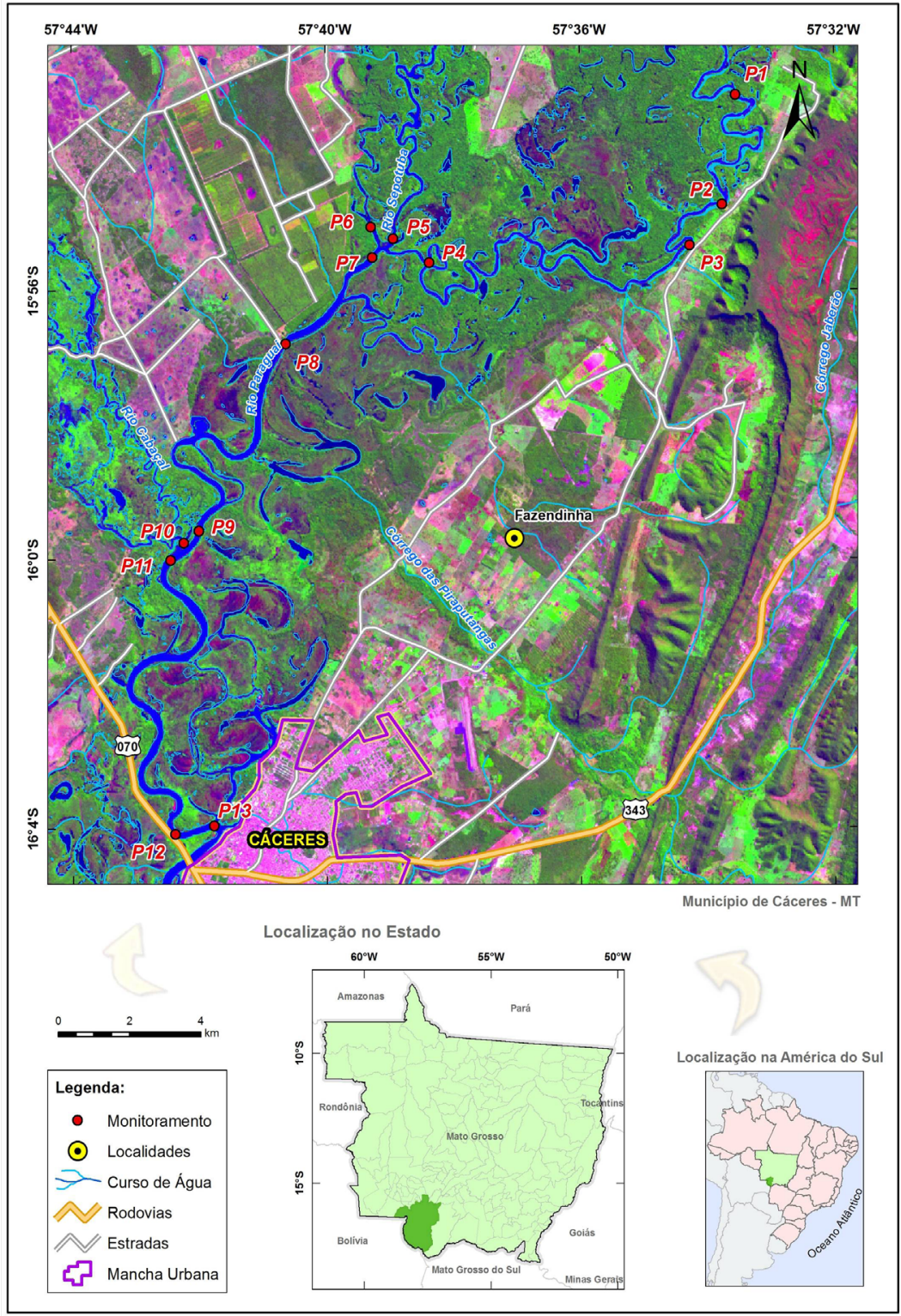

Fonte: Leandro (2015). 
Por fim, para cada ano pesquisado, as imagens classificadas foram processadas no software ArcGIS 9.3, no formato shapefile, para edição dos layouts dos mapas temáticos e para quantificação das classes temáticas utilizando-se a calculadora de atributos (Pessoa et al., 2013a).

\section{Resultados e discussão}

De acordo com o Código Florestal Brasileiro, as áreas marginais de cursos d'água são Áreas de Proteção Permanente (APPs) e, por isso, não poderiam ser utilizadas. A exceção seria somente quando fosse de interesse público. No Brasil, a Legislação Ambiental é bem restritiva, mas apesar desse rigor, a falta de planejamento urbano, de fiscalização de órgãos responsáveis e às pressões de atividades antrópicas vêm reduzindo cada vez mais essas áreas (Silva; Souza, 2012).

O termo "corredor fluvial” foi proposto por Souza (2004) ao considerar a interação existente entre o canal principal do rio Paraguai com seus canais secundários e feições morfológicas, bem como a sua dinâmica que corrobora para a migração do curso principal ao longo da planície de inundação. A largura do sistema varia de 3 a 7 km, a depender do compartimento e padrão de canal, conforme Silva et al. (2008).

Nesse sentido, para a preservação da mata ciliar do rio Paraguai com base nos parâmetros apontados pelo Código Florestal Brasileiro, precisa ser considerada a interação hidromorfodinâmica do sistema rio-planície de inundação. Isso porque a sua complexidade em função dos ciclos de cheia e vazante, da dinâmica morfológica com a migração lateral do canal e do surgimento de novos canais deve ser avaliada para a efetivação da Legislação Ambiental.

Diante do exposto, foram identificadas cinco classes principais de cobertura e duas classes de uso/ocupação da terra. O domínio Savana, também chamado de Cerrado, se desenvolve na área de estudo na forma de contato e encraves, ocorrendo em meio à Floresta Aluvial, com destaque para três formações: Savana Florestada, Savana Arborizada e Savana Gramíneo-Lenhosa. A quinta classe refere-se à Lâmina D’Água com cursos principais, baías, lagoas, furados e outras feições típicas do Pantanal Mato-Grossense. Associada às tipologias de uso e ocupação destacam-se as classes de Influência Urbana e Pecuária que, no período analisado, apresentaram expansão em suas áreas (Figura 2). 
Figura 2 - Espacialização e evolução temporal das classes antropizadas em ambientes de cobertura vegetal
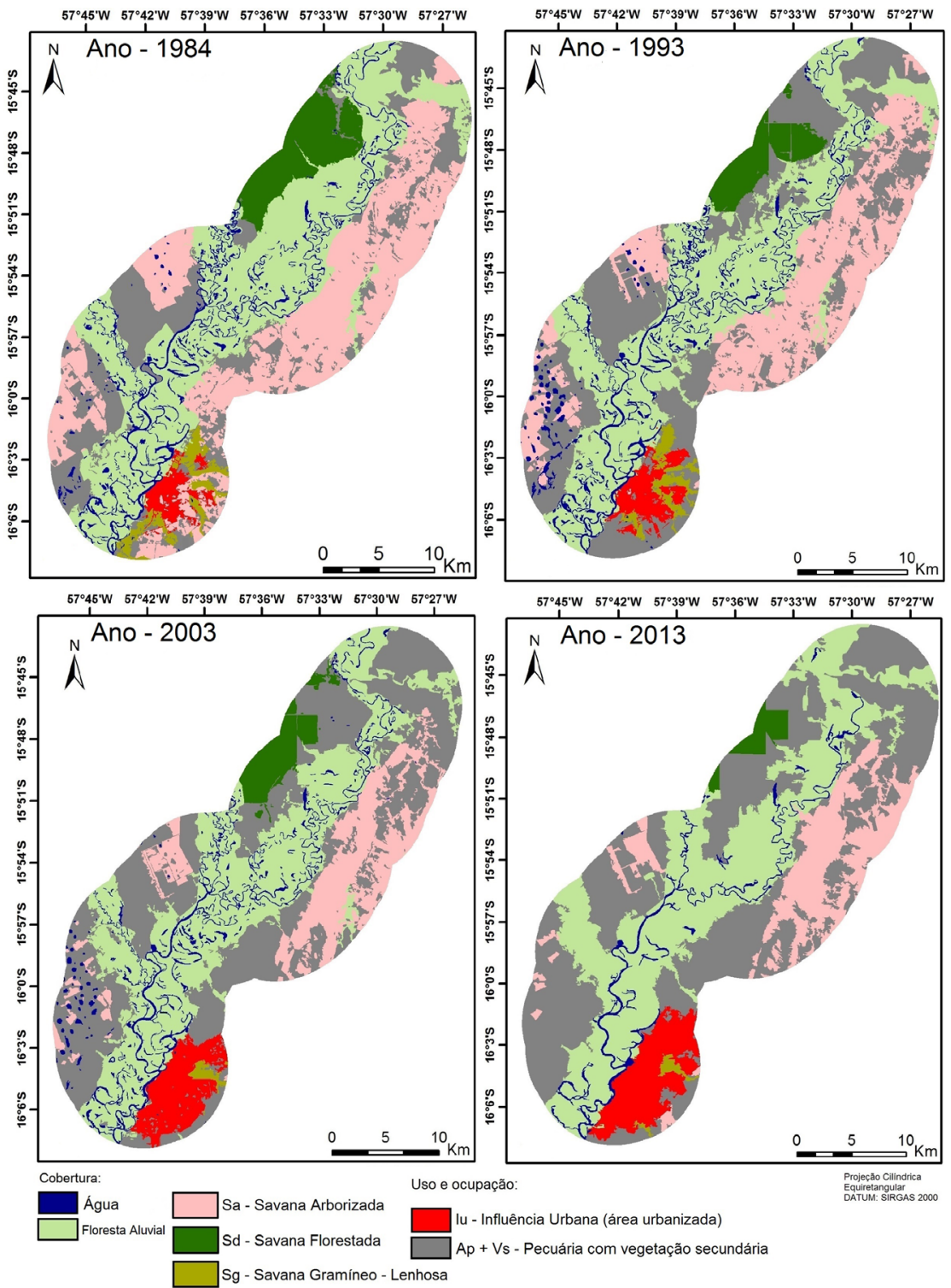

Fonte: Os autores (2015) 
Os anos de 2003 e 2013 apresentaram maior precisão quanto à definição das classes espacializadas conforme o Índice Kappa. Neste caso específico, o valor encontrado foi de 1 para o ano de 2003, o que é considerado excelente no que se refere à correspondência com a realidade, bem como o ano de 2013, que obteve valor de 0,87. A acurácia global para os anos de 1984 e 1993 apresentou desempenho superior a 50\%, considerado aceitável conforme Landis; Koch (1977) e Silva (2003). Os anos de 2003 e 2013 foram os anos com menor confusão média corroborando com o Índice Kappa (Tabela 1).

Tabela 1 - Precisão dos mapeamentos a partir de parâmetros estatísticos

\begin{tabular}{c|c|c|c|c}
\hline Indicador & $\mathbf{1 9 8 4}$ & $\mathbf{1 9 9 3}$ & $\mathbf{2 0 0 3}$ & $\mathbf{2 0 1 3}$ \\
\hline Acurácia Global (\%) & 58,55 & 53,17 & 100 & 90,76 \\
\hline Confusão Média (\%) & 41,45 & 46,83 & 0,0 & 9,24 \\
\hline Índice Kappa & 0,34 & 0,31 & 1,0 & 0,87 \\
\hline
\end{tabular}

Fonte: Dados obtidos em trabalho de gabinete (2015).

A classe Savana Arborizada é composta pelas formações de Campo, Cerrado e Cerrado Aberto, por isso há que se considerar a diversidade de espécies vegetais. Tal diversidade apresenta relação com os elementos abióticos, a exemplo da declividade e tipos de solo. A Floresta Aluvial é composta por espécies arbóreas, arbustivas e herbáceas e por isso apresenta fragilidade ambiental por estar associada à dinâmica hidrológica/ morfológica no corredor fluvial. Nesse sentido, o contato entre as duas classes deve ser considerado para a implantação de atividades econômicas, principalmente a Pecuária (Figura 3). 
Figura 3 - Formações de vegetação na área de estudo
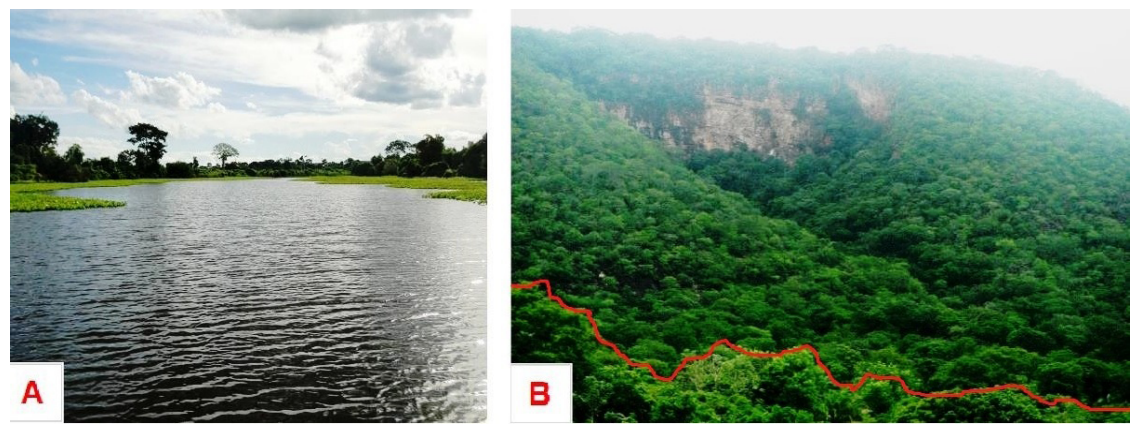

Legenda: A) Tensão ecológica associada ao pulso de inundação no rio Paraguai B) Transição entre Floresta Aluvial e Savana Arborizada em ambientes dissecados da Província Serrana.

Fonte: Leandro (2014).

Entre os anos de 1984 a 2013 a dinâmica de uso e ocupação pelas classes de antropização ocorreu de forma expansiva, sobretudo da atividade Pecuária. Em compensação, as classes de cobertura vegetal foram e vêm sendo suprimidas. Em 1984 havia predomínio da Floresta Aluvial no corredor fluvial com 36,53\% em contato com a Savana Arborizada com $28,36 \%$ (Tabela 2). As alterações antrópicas na paisagem, relacionadas à retirada da cobertura vegetal, predominaram em posições mais baixas do relevo. As áreas de pastagem, destinadas à Pecuária, ocupam áreas originalmente recobertas pela Floresta Aluvial do corredor fluvial com declividade entre 0 a 3\% e áreas de entorno na Província Serrana.

Tabela 2 - Distribuição dos valores em área e porcentagem das classes mapeadas

\begin{tabular}{c|c|c|c|c|c|c|c|c}
\hline \multirow{2}{*}{ Classes } & \multicolumn{2}{|c|}{1984} & \multicolumn{2}{c|}{1993} & \multicolumn{2}{c|}{$\mathbf{2 0 0 3}$} & \multicolumn{2}{c}{2013} \\
\cline { 2 - 10 } & $\mathbf{K m}^{\mathbf{2}}$ & $\%$ & $\mathbf{K m}^{\mathbf{2}}$ & $\%$ & $\mathbf{K m}^{2}$ & $\%$ & $\mathbf{K m}^{\mathbf{2}}$ & $\%$ \\
\hline Lâminas d'água & 46,03 & 5,38 & 49,80 & 5,83 & 43,5 & 5,09 & 23,46 & 2,74 \\
\hline Sg - Savana Gramíneo-Lenhosa & 16,99 & 1,99 & 13,71 & 1,60 & 3,64 & 0,43 & 3,46 & 0,40 \\
\hline Sd - Savana Florestada & 57,12 & 6,68 & 36,01 & 4,21 & 31,81 & 3,72 & 13,75 & 1,61 \\
\hline Sa - Savana Arborizada & 242,41 & 28,36 & 185,14 & 21,66 & 110,87 & 12,97 & 105,24 & 12,31 \\
\hline Fa - Floresta Aluvial & 312,34 & 36,54 & 280,59 & 32,82 & 290,95 & 34,04 & 290,53 & 33,99 \\
\hline Ap+vs - Pecuária + Vegetação & & & & & & & & \\
Secundária & 164,80 & 19,28 & 266,71 & 31,20 & 332,53 & 38,90 & 365,35 & 42,74 \\
\hline Iu - Influência Urbana & 15,15 & 1,77 & 22,87 & 2,68 & 41,53 & 4,86 & 53,04 & 6,20 \\
\hline
\end{tabular}

Fonte: Dados obtidos em trabalho de gabinete (2015). 
No ano de 1993, observa-se a supressão da Savana Florestada em substituição por Pastagem, bem como de áreas da Savana Arborizada na porção Leste em toda a faixa da Província Serrana. Cabe destacar que a Floresta Aluvial dos afluentes de pequeno porte a margem esquerda do rio Paraguai foi majoritariamente retirada. Os fragmentos presentes no baixo curso são mantidos devido à inundação periódica que ocorre na planície de inundação do rio Paraguai e no processo de retroalimentação de seus tributários. Contudo, a atividade pecuária é desenvolvida no período de estiagem com o modelo extensivo, ou seja, o gado é alimentado em pastagens nativas.

Na porção Sul entre 1984 a 1993 foi verificada a expansão do perímetro urbano de Cáceres, o que coincidiu com a fragmentação da Savana Gramíneo-Lenhosa. Cruz e Souza (2016) atribuíram a expansão da malha de Cáceres ao aumento e transferência da população para o sítio urbano. Conforme os autores, a evolução da configuração territorial implicou em impactos ambientais nos córregos urbanos, sobretudo em suas áreas de preservação permanente e em seus leitos maiores. Como resultado, ocorre a despadronização na dinâmica não só desses afluentes "urbanizados", mas também do rio Paraguai e de suas feições morfológicas (baías e canais secundários), na medida em que as descargas sólidas e vazão foram alteradas.

Conforme Cruz (2013), no período entre 1984 a 1999 a cidade de Cáceres deixou de ter uma forma definida, anterior a 1984 e/ou compacta, imposta pelo seu sítio, com novas formas e contornos, assumindo característica de expansão dispersa, o que indica a presença de diversos pequenos núcleos (bairros) isolados; porém, próximo à área central. Contudo, no ano de 2003, observa-se uma homogeneidade parcial do perímetro urbano da cidade de Cáceres associado ao preenchimento de "vazios urbanos" mencionados pelo autor supracitado.

A expansão urbana de Cáceres ocorreu ainda no sentido Sul, ao longo do rio Paraguai em substituição de áreas destinadas anteriormente à Pecuária e em áreas de Floresta Aluvial. Mendes (2009) destacou a inauguração do Conjunto Habitacional "Vitória Régia" fomento à implantação da ZPE - Zona de Processamento de Exportação, lançamento da obra da construção de um novo aeroporto (internacional) de Cáceres, construção de pontes, aterro das margens do Córrego Sangradouro na área urbana, construção de vias paralelas à BR-070 no perímetro urbano, entre outros. 
No ano de 2013, ocorreu a concretização do perímetro urbano. No entanto, resultou em processo de desenvolvimento de forma negativa nas diversas frações territoriais da cidade, principalmente no que tange à ocupação de áreas impróprias e/ou de risco como margens dos córregos urbanizados (Cruz; Souza, 2016). A expansão urbana de Cáceres ao longo do corredor fluvial do rio Paraguai na margem esquerda interferiu nos processos morfológicos e hidrossedimentológicos em vários ambientes fluviais. A exemplo das baías do Malheiros na área central e da baía do Sadao nos limites do bairro Jardim das Oliveiras.

No período entre 2003 a 2013 ocorreu o menor percentual de alterações na Paisagem da área de estudo com 10,38\%. As classes que apresentaram maior mudança foram Lâmina d’Água, com redução em área, e Pecuária, com acréscimo em área (Tabela 3). A expansão do perímetro urbano no período teve acúmulo de 4,43\%, com destaque para o período entre 1993 a 2003 associados à supressão da Savana Gramíneo-Lenhosa, bem como a incorporação de áreas anteriormente destinadas a Pecuária, presentes no limite entre as zonas urbana e rural.

Tabela 3 - Mudanças em área das classes mapeadas por período

\begin{tabular}{c|c|c|c|c|c|c|c|c}
\hline \multirow{2}{*}{ Classes } & \multicolumn{2}{|c|}{1984 a 1993 } & \multicolumn{2}{c|}{$\mathbf{1 9 9 3}$ a 2003 } & \multicolumn{2}{c|}{$\mathbf{2 0 0 3}$ a $\mathbf{2 0 1 3}$} & \multicolumn{2}{c}{$\begin{array}{c}\text { Balanç0 em 29 } \\
\text { anos }\end{array}$} \\
\cline { 2 - 9 } & $\mathbf{K m}^{2}$ & $\%$ & $\mathbf{K m}^{\mathbf{2}}$ & $\%$ & $\mathbf{K m}^{\mathbf{2}}$ & $\%$ & $\mathbf{K m}^{\mathbf{2}}$ & $\%$ \\
\hline Lâminas d'água & $+3,77$ & $+0,45$ & $-6,30$ & $-0,74$ & $-20,04$ & $-2,35$ & $-22,57$ & $-2,64$ \\
\hline $\begin{array}{c}\text { Sg - Savana Gramíneo- } \\
\text { Lenhosa }\end{array}$ & $-3,28$ & $-0,39$ & $-10,07$ & $-1,17$ & $-0,18$ & $-0,03$ & $-13,53$ & $-1,58$ \\
\hline Sd - Savana Florestada & $-21,11$ & $-2,47$ & $-4,20$ & $-0,49$ & $-18,06$ & $-2,11$ & $-43,37$ & $-5,07$ \\
\hline Sa - Savana Arborizada & $-57,27$ & $-6,73$ & $-74,27$ & $-8,69$ & $-5,63$ & $-0,66$ & $-137,17$ & $-16,05$ \\
\hline Fa - Floresta Aluvial & $-31,75$ & $-3,72$ & $+10,36$ & $+1,22$ & $-0,42$ & $-0,05$ & $-21,81$ & $-2,55$ \\
\hline $\begin{array}{c}\text { Ap+vs - Pecuária + } \\
\text { Vegetação Secundária }\end{array}$ & $+101,91$ & $+11,92$ & $+65,82$ & $+7,70$ & $+32,82$ & $+3,84$ & $+200,55$ & $+23,46$ \\
\hline lu - Influência Urbana & $+7,72$ & $+0,91$ & $+18,66$ & $+2,18$ & $+11,51$ & $+1,34$ & $+37,89$ & $+4,43$ \\
\hline $\begin{array}{c}\text { TOTAL - Mudanças na } \\
\text { Paisagem com perdas e } \\
\text { acúmulos }\end{array}$ & 226,81 & 26,59 & 189,68 & 22,19 & 88,66 & 10,38 & 476,89 & 55,78 \\
\hline
\end{tabular}

Fonte: Dados obtidos em trabalho de gabinete (2015).

As áreas homogêneas de Savana Arborizada constituem a cobertura vegetal na Província Serrana de Cáceres, porção Leste. Com relação a essa classe foi registrada redução em área com -16,05\% no período de 29 anos, sobretudo na base dos flancos, áreas de contato entre as anticlinais 
e sinclinais (Tabela 3). Nesse caso, o fator topográfico contribui para manutenção da cobertura vegetal, tendo em vista que as serras apresentam gradiente entre 20,1 a $45 \%$ chegando a $75 \%$.

A classe Floresta Aluvial apresentou o menor índice de redução para o período de 2003 a $2013 \mathrm{com}-0,05 \%$ e o valor de perda no período de 29 anos foi de $-2,55 \%$. Os valores obtidos foram aparentemente baixos, quando comparados às classes de Savana. Mas quando se considerou a retirada da cobertura vegetal das margens do rio Paraguai, conforme constatado in loco, verificou-se que extensas faixas não possuem a cobertura ciliar.

A "manutenção" da cobertura vegetal com a Floresta Aluvial pode ser explicada ainda pelos pulsos de cheia que inviabiliza o desenvolvimento de monoculturas, por exemplo, quando associado aos tipos de solo com baixa fertilidade e resistência, tais como Neossolos Quartzarênicos e Flúvicos. Todavia, destaca-se que a pecuária extensiva é desenvolvida em ambientes sujeitos a inundação da Floresta Aluvial com o chamado gado pantaneiro (Figura 4).

Figura 4 - Uso atual associado ao modelo produtivo regional
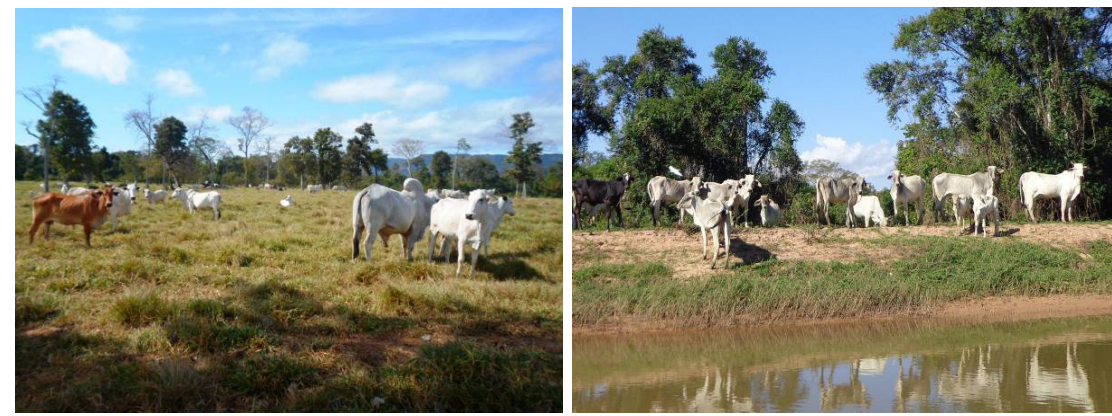

Legenda: A) Agropecuária em ambientes originalmente savânicos da Província Serrana e B) sujeitos a inundação na baía Comprida, rio Paraguai.

Fonte: Os autores (2014).

A classe Espelho d'água corresponde ao rio Paraguai e seus afluentes de maior porte, como os rios Sepotuba e Cabaçal, e ainda a feições morfológicas na planície de inundação. Nos mapeamentos de 1984 e 1993 a área ocupada por água correspondeu a 5,38\% e 5,83\%, o que equivaleu a um acréscimo de 0,45\%. Enquanto que nos anos de 2003 e 2013 registrou-se redução com 5,09\% e 2,74\%, respectivamente (Tabelas 3 e 4). Destaca-se que no período de 2003 a 2013 inúmeras feições morfológicas 
desapareceram, possivelmente associadas à dinâmica do rio Paraguai com anexo de baías e canais secundários a planície de inundação, colmatação, entre outros processos. Outro fator que pode explicar a variação em área das lâminas d'água é o período do ano mais úmido de 1984 a 1993 e mais seco de 2003 a 2013.

Silva e Souza (2012) constataram que, a urbanização, o crescimento populacional, o incremento do turismo e a quantidade de embarcações no rio são fatores que, interferem diretamente na dinâmica do rio Paraguai. Conforme os autores, os problemas com o assoreamento do canal, contaminação da água e erosão marginal são os principais vetores de degradação dos ambientes fluviais em Cáceres, Mato Grosso. Contudo, a erosão marginal é motivo de maior preocupação para a população local. Principalmente, pela perda de terrenos associado aos processos de erosão marginal no perímetro urbano do município.

\section{Uso das margens e do canal}

A localização estratégica da cidade de Cáceres, ou seja, a margem esquerda do rio Paraguai, propiciou uma relação histórica entre a população e o rio que perdura até os dias atuais, principalmente do ponto de vista econômico e social (Silva; Souza, 2012). As tipologias de uso nas margens e no canal do rio Paraguai estão culturalmente ligadas à pesca de subsistência com embarcações de pequeno porte e pesca de barranco, principalmente desenvolvidas pelos ribeirinhos, bem como a pesca profissional. Contudo, constatasse, a partir dos trabalhos de campo realizados durante a pesquisa, a inserção de outras modalidades com alto impacto ambiental.

Neves et al. (2012) introduziram a temática destacando que, no Pantanal Mato-Grossense, na unidade de Cáceres, a pesca profissional e turística é desenvolvida principalmente no corredor fluvial do rio Paraguai e seus principais afluentes (rios Sepotuba, Cabaçal, Jauru e o córrego Padre Inácio). Os autores também apontam que essa atividade tem gerado, há muitos anos, emprego e renda para diversos segmentos econômicos, benefícios sociais e igualmente problemas de ordem ambiental.

As principais atividades desenvolvidas nas margens e/ou no leito do rio Paraguai, foram agrupadas em três setores. O primeiro pode ser subdivido em pesca de barranco com cevas em flutuantes ou de barranco, 
bem como embarcada com modelos a remo ou a motor. No segundo, lazer, as margens são utilizadas no período de vazante com a instalação de acampamentos temporários e ranchos ou casas de veraneio. O uso pecuário com modelo intensivo é visível em alguns trechos de barranco alto, sobretudo em áreas de terraços fluviais ou ainda em ambientes alagáveis na modalidade extensiva.

As confluências e baías são consideradas os melhores pontos de pesca, principalmente em ambientes de baías formadas pela dinâmica dos tributários e do rio Paraguai. Sobre isso, Neves et al. (2012), a partir de espacialização das rodadas (pontos de pesca) no rio Paraguai, identificaram que a maioria dos pontos de pesca tem seu início próximo a saída de baías. Isso porque concentram espécies de pequeno porte como o lambari (Astyanax), pacu-peva (Metynnis maculatus), entre outros que são iscas que atraem peixes de grande porte, ou seja, considerados nobres pelos pescadores (Figura 5).

Figura 5 - Acampamentos em casa de apoio de pescadores no rio Paraguai, Cáceres - Mato Grosso
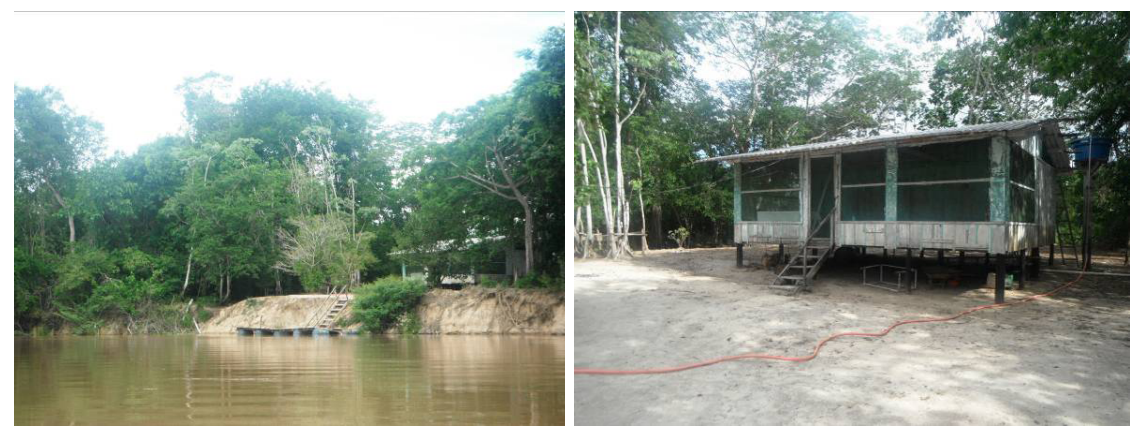

Fonte: Os autores (2014).

A proximidade dos pontos P12 e P13 ao perímetro urbano de Cáceres facilita o acesso ao rio Paraguai pela BR-070. Na margem côncava de P12 (margem direita) é desenvolvida a pesca de barranco, já a margem convexa (margem esquerda) é utilizada por banhistas no período de vazante. Em $\mathrm{P} 13$, em ambas as margens os usos estão ligados à pesca de barranco.

Os resultados obtidos podem ser relacionados a diversos fatores como tipo e morfologia de margem, período do ano (cheia, vazante ou transição), atividades socioeconômicas desenvolvidas e acessibilidade 
ao recurso hídrico. Os tipos de margem e morfologia caracterizam-se por côncavas e convexas associado ao padrão de canal meandrante. Com relação às obras de engenharia, no Ponto P12 foi iniciada a construção de um paredão de pedras com extensão de 800 a $900 \mathrm{~m}$ e profundidade de $8 \mathrm{~m}$ (técnica de "enrocamento") com o objetivo de conter os processos erosivos que ameaçam a BR-070 (Figura 6).

Figura 6 - Início das obras para contenção dos processos erosivos no trecho da BR-070 (2014)

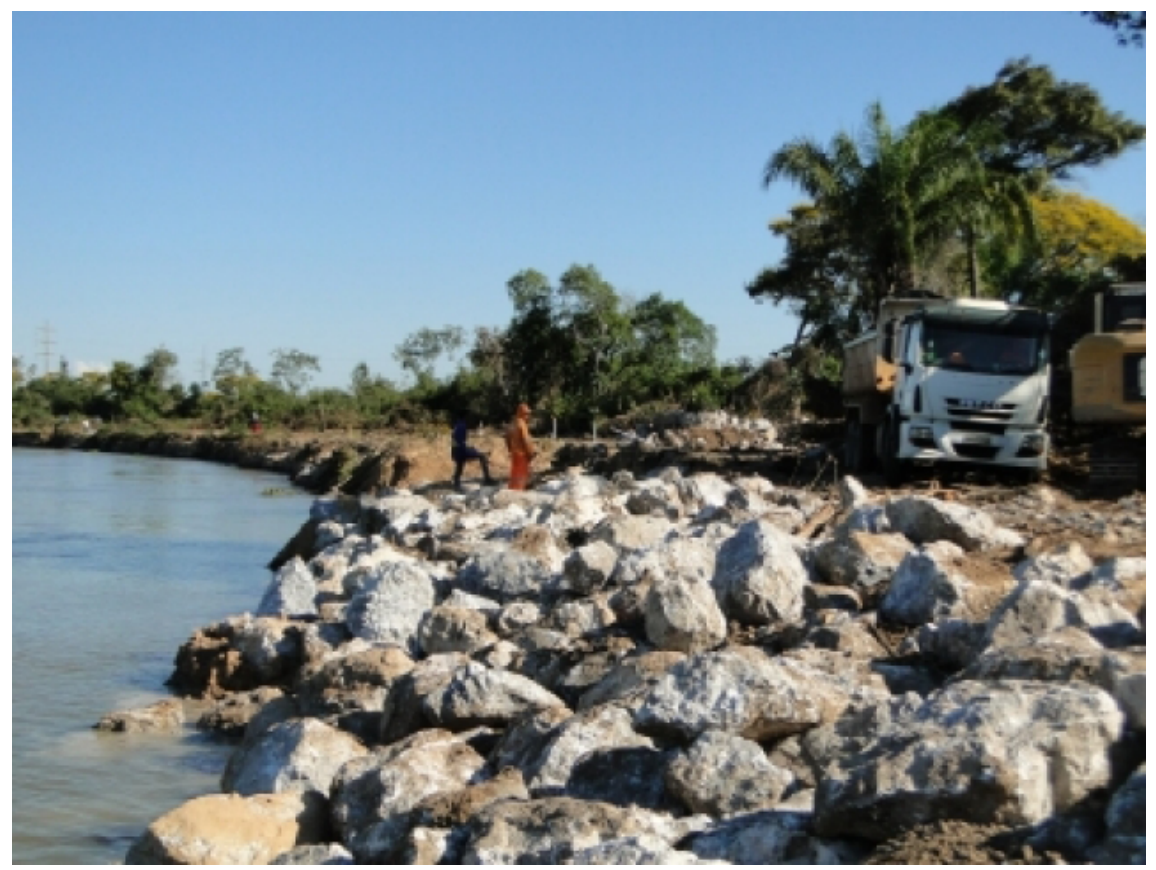

Fonte: Jornal Oeste (2014).

A colocação de uma carga de fragmentos rochosos, ou enrocamentos, que possa reter a massa do terreno, mas que permita a drenagem da água, é um dos métodos utilizados para controle dos desmoronamentos (Penteado, 1983 apud Holanda et al., 2009). Os enrocamentos são obras de engenharia usadas para o controle da erosão, sendo um, entre vários, dos métodos de proteção das margens dos rios, também chamado de RSP (Rock Slope Protection) ou rip-rap (Holanda et al., 2009). 
Contudo, salienta-se que esse tipo de empreendimento deve considerar as condições geológicas, hidrológicas e outras variáveis ambientais. No caso específico do rio Paraguai, trecho próximo a BR070 em Cáceres, ressalta-se que o embasamento é composto por Aluviões atuais e pela Formação Pantanal, que são altamente permeáveis, bem como por Neossolos Flúvicos (solos aluviais). O segundo ponto se refere à amplitude fluviométrica do sistema fluvial com as águas superficiais e em lençol freático.

O trecho entre os pontos $\mathrm{P} 12$ e $\mathrm{P} 13$ correspondem à margem côncava susceptível a erosão e a face do barranco apresenta morfologia íngreme, fatores que quando associados às características ambientais favorecem quedas de blocos por solapamento basal. Nesse contexto, Holanda et al. (2009) destacam que a eficiência das técnicas utilizadas no controle da erosão é variável em função da feição dos taludes a serem estabilizados, assim como da dinâmica natural do rio, podendo ser também alteradas pelas ações antrópicas, a exemplo do rio São Francisco.

Como ocorre nos grandes rios pelo mundo, os enrocamentos ou rip-rap vêm sendo implantados, desde a década de 1980, ao longo das margens dos rios brasileiros, como alternativas para conter o processo de erosão marginal. Para contornar o problema da baixa coesão dos solos aluviais das margens dos rios, normalmente Neossolos Flúvicos, tem sido trabalhado nos taludes locais material granular com diâmetro médio de $70 \mathrm{~cm}$. Esse material não só retém as partículas que foram arrastadas pela erosão subterrânea como também absorve o impacto das ondas sobre a face do barranco, evitando o solapamento de sua base (Holanda et al., 2009). Contudo, quanto ao estado de conservação dos trechos com enrocamento, Holanda et al. (2008) perceberam que grandes extensões do rio São Francisco estão sendo estabilizadas e até mesmo naturalmente revegetadas, embora ocorra solapamento na base, levando a questionamentos sobre a completa eficiência das obras de contenção.

De acordo com Silva e Souza (2012), as transformações observadas nas margens do rio Paraguai em Cáceres tanto no perímetro urbano quanto na área de expansão urbana são reflexos da ocupação desordenada. As autoras, com a utilização do protocolo de avaliação, obtiveram resultados que mostram que houve a predominância dos aspectos "impactados" e "alterados", principalmente nos pontos mais próximos da área urbana de Cáceres, onde há uma intensa pressão de atividades antrópicas. No 
presente estudo foram consideradas como áreas de influência do perímetro urbano o trecho entre P12 e P13 que embora não apresente ocupação fixa é amplamente utilizado pela população local.

Os pontos avaliados por Bühler e Souza (2012) foram classificados como "Natural”, pois, para os autores, na cheia, a elevação do nível fluviométrico do rio Paraguai proporcionou a inundação da planície e a cobertura das margens. Dessa forma, a erosão marginal se tornou menos evidente e a quantidade de solo/substrato exposta diminuiu; outras alterações na calha do rio (muros de arrimo ou canalizações) também ficaram cobertas pela água. Esses fatores devem ter contribuído para que os trechos aparentassem melhores condições de preservação no período de águas altas (cheia). Nesse sentido, Bühler e Souza (2012) salientam ainda que, para cada período do ciclo hidrológico, as tipologias de uso no rio Paraguai variam bem como os impactos associados. Ou seja, a elevação das águas camuflam diversas intervenções no sistema fluvial, como lançamento de esgoto, erosão marginal, dentre outros.

Considerando as mudanças expressivas na calha do rio Paraguai, Souza et al. (2012) sugeriram que, ao propor qualquer tipo de uso direto ou indireto neste trecho, seja considerada a dinâmica fluvial. Conforme os autores, na planície de inundação os maiores problemas ambientais são decorrentes da ocupação das margens, sendo que eles estão relacionados à expansão urbana de Cáceres. Já no canal, os impactos são devidos, principalmente, ao desenvolvimento da navegação no rio Paraguai. O maior impacto observado no leito do rio Paraguai se deve ao atrito das grandes embarcações nas margens do canal.

Nesta perspectiva, as estruturas biogeofísicas do espaço, como suporte em que se alicerça a construção do território, condicionam decisivamente as estratégias de implementação e desenvolvimento das atividades humanas. As características de ordem geológica, topográfica e geomorfológica, assim como as propriedades específicas dos solos, da rede hidrográfica e do clima em nível local e regional, constituem fatores determinantes da organização dos espaços de fixação humana e, como tais, dos espaços produtivos que constituem a base dos sistemas econômicos e sociais (Pedrosa, 2014).

Diante disso, Corradini et al. (2006) atentam para a fragilidade dos ambientes de planície a antropização. Conforme os autores, da mesma forma que as características físicas das unidades geomorfológicas da 
planície controlam a distribuição da vegetação, elas também fornecem diferentes qualidades para o seu uso e ocupação. Estradas, construções, tipo de lavoura ou de plantação são determinadas de acordo com as características de cada unidade. Esse fato estende o conceito de conectividade para além da ocupação natural, envolvendo as atividades socioeconômicas na planície.

\section{Considerações finais}

Na área de estudo, sobretudo no corredor fluvial, o conjunto das unidades de vegetação identificados, com destaque para a Floresta Aluvial com seus extratos, são indicadores da dinâmica morfológica nos ambientes fluviais. As características e composição apresentam relação com os processos de erosão e deposição. Cabe salientar que, há ainda relação com os ciclos de inundação, a exemplo das espécies flutuantes. Os processos de deposição influenciam na sucessão de herbáceas e de espécies arbustivo-arbóreas, com destaque para o Sarã (Sapium obovatum), pois ele em especial indica a estabilização dos depósitos recentes ao longo do rio Paraguai.

Acrescenta-se que a área de estudo é estruturada por ambientes agradacionais da planície de inundação do rio Paraguai e seus afluentes, bem como por ambientes de denudação suave e forte da Província Serrana. Os sistemas geológico/geomorfológicos com ou sem controle estrutural embasam os pedoambientes com seus subconjuntos vegetais predominantemente savânicos.

Nesse sentido, as atividades econômicas devem ser planejadas e desenvolvidas conforme a potencialidade local, pois qualquer pressão poderá causar rupturas no sistema ambientalmente dinâmico e em evolução. Nesse contexto, os tipos de uso/ocupação devem ser delineados conforme as limitações de cada unidade ambiental identificada, bem como a partir de seus processos modeladores.

A percepção da dinâmica ambiental é fundamental para ordenar a ocupação, os tipos de uso e sua conservação, pois os ambientes são susceptíveis a mudanças de ordem natural. Nesse sentido, a expansão da atividade pecuária e monoculturas podem alterar a dinâmica do rio Paraguai com o aporte de sedimentos produzidos não só na área de estudo, 
mas no contexto de bacia hidrográfica, na medida em que os processos de erosão e deposição de sedimentos são potencializados.

\section{Referências}

BAYER, M. Dinâmica do transporte, composição e estratigrafia dos sedimentos da planície aluvial do rio Araguaia. 2010. 82 f. Tese (Doutorado em Ciências Ambientais) - Universidade Federal de Goiás, Goiânia, 2010.

BAYER, M.; ZANCOPÉ, M. H. C. Ambientes sedimentares da planície aluvial do rio Araguaia. Revista Brasileira de Geomorfologia, São Paulo, v.15, n. 2, p. 203220, 2014.

BORGES, C. Z. Erosão marginal no rio Paraná após a conclusão do reservatório da UHE Sérgio Motta (Porto Primavera) a jusante da barragem. 2004. $50 \mathrm{f}$. Dissertação (Mestrado em Geografia) - Universidade Estadual de Maringá, Maringá, 2004.

BÜHLER, B. F.; SOUZA, C. A. Aspectos sedimentares do rio Paraguai no perímetro urbano de Cáceres - MT. Geociências, v. 31, n. 3, p. 339-349, 2012.

COELHO, A. L. N. Alterações hidrogeomorfológicas no Médio-Baixo Rio Doce/ ES. 2007. 227 f. Tese (Doutorado em Geografia) - Instituto de Geociências, Universidade Federal Fluminense, Niterói, 2007.

COHEN, J. A. Coefficient of agreement for nominal scales. Educational and Psychological Measurement, v. 20, n.1, p. 37-46, 1960.

COMUNELLO, E. Dinâmica de inundação de áreas sazonalmente alagáveis na planície aluvial do Alto rio Paraná. 46 f. 2001. Dissertação (Mestrado em Ecologia de ambientes aquáticos continentais) - Universidade Estadual de Maringá, Maringá, 2001.

CORRADINI, F. A.; FACHINI, M. P.; STEVAUX, J. C. Controle geomorfológico da distribuição da vegetação ripária do rio Paraná: Parte I - Unidades geomórficas da planície de inundação. Revista UnG - Geociências, v. 5, n. 1, p. 13-21, 2006.

CRUZ, J. S. Ordenamento territorial urbano e suas implicações nos canais de drenagem em Cáceres - Mato Grosso. 114 f. 2013. Dissertação (Mestrado em Ciências Ambientais) - Universidade do Estado de Mato Grosso, Cáceres, 2013.

CRUZ, J. S.; SOUZA, C. A. A questão urbana na bacia do Alto Paraguai: desenvolvimento urbano e suas implicações nos canais de drenagem em Cáceres/ MT (períodos de 1945 a 2013). Boletim de Geografia, v. 34, n. 3, p. 11-128, 2016.

HOLANDA, F. S. R.; I, P.; OLIVEIRA, V. S. Estabilização de taludes marginais com técnicas de bioengenharia de solos no Baixo São Francisco. Revista Brasileira de Engenharia Agrícola e Ambiental, Campina Grande, v. 12, n. 6, p. 570-575, 2008. HOLANDA, F. S. R.; ROCHA, I. P.; BANDEIRA, A. A; ARAÚJO FILHO, R. N.; RIBEIRO, L. F.; ENNES, M. A. Controle da erosão em margens de cursos d'água: das soluções empíricas à técnica da bioengenharia de solos. R. RA'EGA, Curitiba, n. 17, p. 93-101, 2009. 
IBGE. Instituto Brasileiro de Geografia e Estatística. Manuais técnicos em Geociências: manual técnico da vegetação. 2. ed. Rio de Janeiro: IBGE, 2012. 271 p. (n. 1).

LANDIS, J.; KOCH, G. The measurement of observer agreement for categorical data. Biometrics, v. 33, n. 1, p. 159-174, 1977.

NEVES, S. M. A. S.; NEVES, R. J.; SILVA, A. CRUZ, C. B. M. Pesca de rodada no rio Paraguai - Pantanal de Cáceres - MT, Brasil: geração de subsidio a atividade turística com suporte nas geotecnologias. In: SOUZA, C. A. (Org.). Bacia hidrográfica do rio Paraguai - MT: Dinâmica das águas, uso e ocupação e degradação ambiental. São Carlos: Cubo, 2012. p. 203-209.

PEDROSA, A. S. O contributo da Geomorfologia para a compreensão da construção do espaço geográfico: breves reflexões. Boletim Goiano de Geografia, v. 34, n. 3, p. 423-441, 2014.

PESSOA, S. P. M.; GALVANIN, E. A. D.; NEVES, S. M. A. S. Mapeamento do uso e ocupação da floresta aluvial no rio Paraguai - Barra do Bugres/Mato Grosso. Revista Brasileira de Cartografia, v. 66, n. 6, p. 1295-1303, 2014.

PESSOA, S. P. M.; GALVANIN, E. A. S.; KREITLOW, J. P.; NEVES, S. M. A. S.; NUNES, J. R. S.; ZAGO, B. W. Análise espaço-temporal da cobertura vegetal e uso da terra na interbacia do rio Paraguai médio - MT, Brasil. Revista Árvore, v. 37, n. 1, p. 119-128, 2013a.

ROCHA, P. C. Os processos geomórficos e o estado de equilíbrio fluvial no alto rio Paraná, centro sul do Brasil. Geosul, v. 24, n. 48, p. 154-176, 2009.

SILVA, A. de B. Sistemas de informações eo-referenciadas: conceitos e fundamentos. São Paulo: Unicamp, 2003. 236 p.

SILVA, A.; SOUZA FILHO, E. E.; CUNHA, S. B. Padrões de canal do rio Paraguai na região de Cáceres (MT). Revista Brasileira de Geociências, v. 38, n. 1, p. 167177. 2008.

SILVA, R. V.; SOUZA, C. A. Ocupação e degradação na margem do rio Paraguai em Cáceres, Mato Grosso. Revista Brasileira de Gestão e Desenvolvimento Regional, v. 8, n. 1, p. 125-152, 2012.

SOUZA, C. A. Dinâmica do corredor fluvial do rio Paraguai entre a cidade de Cáceres e a Estação Ecológica da ilha de Taiamã-MT. 2004. 173 f. Tese (Doutorado em Geografia) - Centro de Ciências Matemáticas e da Natureza, Universidade Federal do Rio de Janeiro - UFRJ, Rio de Janeiro, 2004.

SOUZA, C. A.; PIERANGELI, M. A.; SOUSA, J. B. Análise espaço-temporal do corredor fluvial do rio Paraguai no trecho entre Cáceres e a ilha Taiamã/MT. Revista Brasileira de Cartografia, v. 64, n. 5, p. 551-564, 2012.

VENDRAMINI, W. J.; SOUZA, C. A.; SOUZA, M. A. Assoreamento na baía do Sadao no rio Paraguai - Cáceres - Mato Grosso. Cadernos de Geociências, v. 9, n. 2, p. 85-93, 2012. 
pelo Programa de Pós-Graduação em Geografia, Faculdade de Ciências e Tecnologia, Campus de Presidente Prudente, Universidade Estadual Paulista "Júlio de Mesquita Filho". https://orcid.org/0000-0001-9349-5337

Flávio Rodrigues do Nascimento - Licenciado e Bacharel em Geografia pela Universidade Federal do Ceará. Mestre em Geografia pela Universidade Estadual do Ceará. Doutor em Geografia pela Universidade Federal Fluminense. Professor adjunto do curso de Graduação e do Programa de Pós-Graduação em Geografia da Universidade Federal do Ceará. https://orcid.org/0000-0002-7382-6853

Célia Alves de Souza - Licenciada e Bacharel em Geografia pela Universidade Federal de Mato Grosso do Sul. Mestre em Geografia pela Universidade Federal do Rio de Janeiro. Doutora em Geografia pela Universidade Federal do Rio de Janeiro. Pós-doutora pela Universidade Federal Fluminense. Professora adjunto do curso de Graduação em Geografia e dos Programas de Pós-Graduação em Geografia e em Ciências Ambientais da Universidade do Estado de Mato Grosso. https://orcid.org/0000-0002-7382-6657

\section{Contribuições dos autores}

Gustavo Roberto dos Santos Leandro e Célia Alves de Souza construíram as bases de dados a partir dos trabalhos de campo. As análises espaciais das principais classes de uso e ocupação da terra foram realizadas por Gustavo Roberto dos Santos Leandro e Flávio Rodrigues do Nascimento. Todos os autores participaram da escrita do texto - estruturação, base bibliográfica, escolha dos procedimentos.

Recebido para publicação em 28 de dezembro de 2018 Aceito para publicação em 22 de fevereiro de 2019 Publicado em XX de XXXX de XXXX 